\title{
Comparison of Nurses' Image in Korean Online Newspaper Articles before and after COVID-19: A Text Mining Analysis
}

\author{
Jeongmin $\mathrm{Ha}^{1}$, Dahye Park ${ }^{2}$ \\ ${ }^{1}$ PhD., Department of Nursing, Chung-Ang University, Dongjak-gu, Seoul, 06974, Korea, ${ }^{2}$ Professor, Department \\ of Nursing, Semyung University, Jecheon-si, Chungbuk, 27136, Korea
}

\begin{abstract}
Background/Objectives: This study investigated nurse-related keywords which were presented together with nurse on phrase, clauses or sentence of documents or conversations in the Korea online newspaper articles.

Methods/Statistical analysis: Text mining, which is a common method of analysis for large datasets, was used to analyze the changes in nurses' image before and after COVID-19. A total of the linking words with nurse were calculated by the number of presentation on online newspaper article in Naver before and after COVID-19. In order to identify the meaning of the words, clustering of the collected linking words by categories was analysed and the characteristics of each cluster were classified. Over 5,000 articles were identified as targets for a keyword analysis.

Findings: The most frequently presenting words were hospital, medical and patient. Before COVID-19, the words related to 'workplace bullying' were highly presented and after COVID-19, the words related to 'care' were highly presented.

Improvements/Applications: With analyzing the trends of changes and characteristics of words by COVID-19 and clusters, we attempted to investigate the image of nurse that the public think and feel about nurse.
\end{abstract}

Keywords: Nurse' image; Online newspaper; COVID-19; Text mining analysis

\section{Introduction}

The World Health Organization (WHO) declared that COVID-19 entered the pandemic phase on March $11,2020^{[1]}$. As of May 24, 2020, there were 5,201,549 confirmed cases of COVID-19 and 337,405 deaths across the world ${ }^{[2]}$, as well as 11,190 confirmed cases and 266 deaths in Korea, where the first confirmed case occurred

\footnotetext{
Corresponding Author:

Dahye Park

Professor, Department of Nursing, Semyung

University, Jecheon-si, Chungbuk, 27136, Korea

e-mail: dhpark@semyun.ac.kr

Phone Number: 82-43-649-1588
}

on January 20, $2020^{[3]}$. Since the beginning of this unprecedented public health emergency, nurses around the world have been on the frontlines ${ }^{[4]}$, treating patients suffering from a highly contagious disease. A key aspect of being on the frontlines during this pandemic is the risk of contracting the virus. Accordingly, the media continues to highlight the role of nurses in responding to the pandemic, leading to an increase in public interest in both nursing and nurses.

Nursing is a patient-oriented, therapeutic interpersonal process, and the rapport between the nurse and patient is a key factor in its success. Therefore, the image that a patient has of nurses is an essential factor in determining whether a therapeutic relationship with 
the patient will be effective. In addition, a positive public image of nurses is associated with increased selfevaluation, self-concept, professional intuition, and job performance and decreased turnover intention among nurses ${ }^{[6-8]}$. Therefore, the public's image of nurses affects the quality of nursing, which in turn affects the quality of public health ${ }^{[9]}$.

In today's rapidly changing society, the public's perception is greatly influenced by the media [10]. Therefore, the depiction of nurses in the media can have a considerable effect on the public's attitudes and behaviors toward nurses ${ }^{[11]}$. Given the link between the public's perception of nurses and the quality of public health, it is worthwhile to evaluate how nurses are portrayed in the media and how the portrayal is received by the public.

The MERS outbreak in Korea demonstrated the crucial role of the media in the public's perception of nurses and nursing. In fact, COVID-19 is not the first time in recent history that Korean nurses have been on the frontlines of a public health crisis. In the MERS outbreak, Korean nurses worked day and night to protect the lives of the public despite considerable financial and non-monetary losses ${ }^{[12]}$. However, several aspects of the country's response to MERS, including the information policy that prevented the public from obtaining accurate information through the media, the untimely response to MERS from the government, and the spreading of false information regarding the inadequate treatment of patients or neglected medical examinations, led to the perception that healthcare providers, including nurses, had become unreliable ${ }^{[12]}$.

In the ever-changing situation created by COVID-19, no data have emerged to quantify the image of nurses or the public's trust in nurses. News media is the most influential medium in forming public awareness of nurses [13]. Particularly in Korea, the internet and smartphones are integral to everyday life ${ }^{[14]}$, and the public accesses news mostly via the internet ${ }^{[15]}$. Therefore, a textual analysis of online newspaper articles may provide valuable insights into the image of nurses, and is suitable for analyzing the medical service needs of consumers. Given that over four months have elapsed since Korea had its first confirmed case of COVID-19, there is also a sufficient amount of data from online news sources to evaluate the portrayal of nurses in the media.

There have been studies of nurses' image in various media, including internet newspapers ${ }^{[16,17]}$, hospital newspapers ${ }^{[18]}$, and the internet and social media [19], but studies of nurses' image in television [20-23] predominate. However, data analyzed in these studies predate COVID-19 and do not reflect the changes in the image of nurses since the beginning of the COVID-19 pandemic. A textual analysis of online news articles preand post-COVID-19 is expected to capture the breadth of images of nurses both within and outside of the nursing industry and provide a basis for a connection of relevant social issues or nursing policies. Therefore, this study aimed to help develop a strategy for the nursing community to deliver a desirable image of themselves and their profession by identifying the portrayals of nurses highlighted in the media.

\section{Method}

\section{Purpose of research}

Text mining, which is a common method of analysis for large datasets, was used to analyze the changes in nurses' image before and after COVID-19. This study had two research goals. The first goal was to identify the associated words that appear in online news articles regarding nurses. The second goal was to analyze the nurse-related words to understand how the image of nurses has changed after COVID-19.

\section{Data collection}

Data for this study were collected from Korean portal websites and social media. All phrases and sentences containing the word "nurse" were collected from the Naver news portal, which features articles from the largest share of news organizations in Korea, to extract words related to "nurse" [24]. 
Data were collected for two periods. First, data were collected from January 1, 2017 - December 11, 2019 for the analysis of nurses' image before the occurrence of COVID-19. Second, data were collected from December 12, 2019 to May 10, 2020 for analysis of nurses' image after the occurrence of COVID-19.

In the data collection phase, online news article data was collected from Naver using the Python algorithm for online data crawling. After collection, the data were stored in a form that could be analyzed.

\section{Data analysis}

In the next text mining stage, the data were preprocessed and analyzed using a range of analytic techniques commonly used in text mining. First, the data were preprocessed using a Python algorithm for natural language processing and morpheme analysis. The purpose of preprocessing the data was to analyze the grammar and structure of the text. Next, the textual data were converted into a term-document-matrix, a structured data type, and processed into a form suitable for analysis.

The extracted words from the processed data were then analyzed. Specifically, the words were classified by morphological analysis, frequency, and correlation analysis and visualization, and all related words appearing simultaneously with the word "nurse" were classified. Also, to examine the topics relevant to nurses discussed by the writers of the articles, the extracted words were clustered into categories of words with similar characteristics. The final nurse-related words (except for stop words) were arranged by three researchers to classify words with similar qualities. If there was a word corresponding to a higher-level concept among the classified related words or if there was a higher-level concept that could be used to refer collectively to a set of related words, the word was used as a characteristic of the corresponding relatedword set group. Similar characteristics of the higherlevel concepts were repeatedly identified to classify the characteristics of the related word set in a step-wise fashion. Through this process, the differences in nurses' image in online newspaper articles before and after COVID-19 were statistically analyzed.

\section{Result}

\section{Nurse-related news articles}

There were 3,410 online news articles before COVID-19 and 1,626 articles after COVID-19 that contained keywords related to the word "nurse." Before COVID-19, Yonhap News had the highest number of articles with 354 cases (10.4\%), followed by Newsis with 348 cases (10.2\%), News1 with 197 cases (5.8\%), KBS with 161 cases (4.7\%), Seoul Economic Daily (SED) with 141 cases (4.1\%), and Kookmin Daily with 133 cases (3.9\%). After COVID-19, Yonhap News had the highest number of articles with 167 cases $(10.3 \%)$, followed by Newsis and News1 with 131 cases $(8.1 \%)$ each, Joins.com with 73 cases $(4.5 \%)$, and KBS and Kookmin Daily with 71 cases (4.3\%) each (Table 1). In summary, over 5,000 articles were identified as targets for a keyword analysis.

Table 1. Number and percentage of nurse-related articles by online newspaper and type

\begin{tabular}{|c|c|c|c|c|c|}
\hline \multirow[b]{2}{*}{ Number } & \multirow[b]{2}{*}{ Newspaper } & \multicolumn{2}{|c|}{ Before COVID-19 ${ }^{1}$} & \multicolumn{2}{|c|}{ After COVID-19² } \\
\hline & & $n$ & $\%$ & $n$ & $\%$ \\
\hline 1 & Yonhap & 354 & 10.4 & 167 & 10.3 \\
\hline 2 & Newsis & 348 & 10.2 & 131 & 8.1 \\
\hline 3 & News1 & 197 & 5.8 & 131 & 8.1 \\
\hline 4 & KBS & 161 & 4.7 & 73 & 4.5 \\
\hline 5 & SED & 141 & 4.1 & 71 & 4.3 \\
\hline 6 & Kukmin Daily & 133 & 3.9 & 71 & 4.3 \\
\hline- & Other & 2076 & 60.9 & 982 & 60.4 \\
\hline
\end{tabular}


${ }^{1} \mathrm{~N}=3,410 .{ }^{2} \mathrm{~N}=1,626$.

2. Visualization of nurse-related keywords

A word cloud was used to visualize the highly relevant keywords from the main nurse-related keywords used in online newspapers before and after COVID-19 (Figure 1).

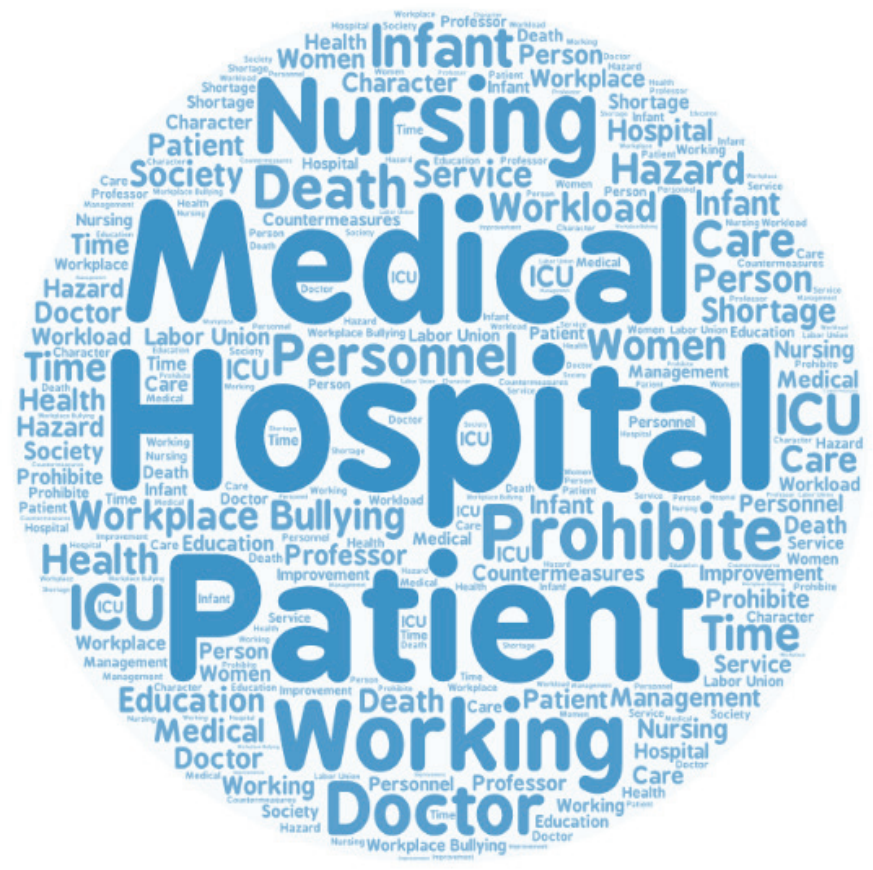

(a)

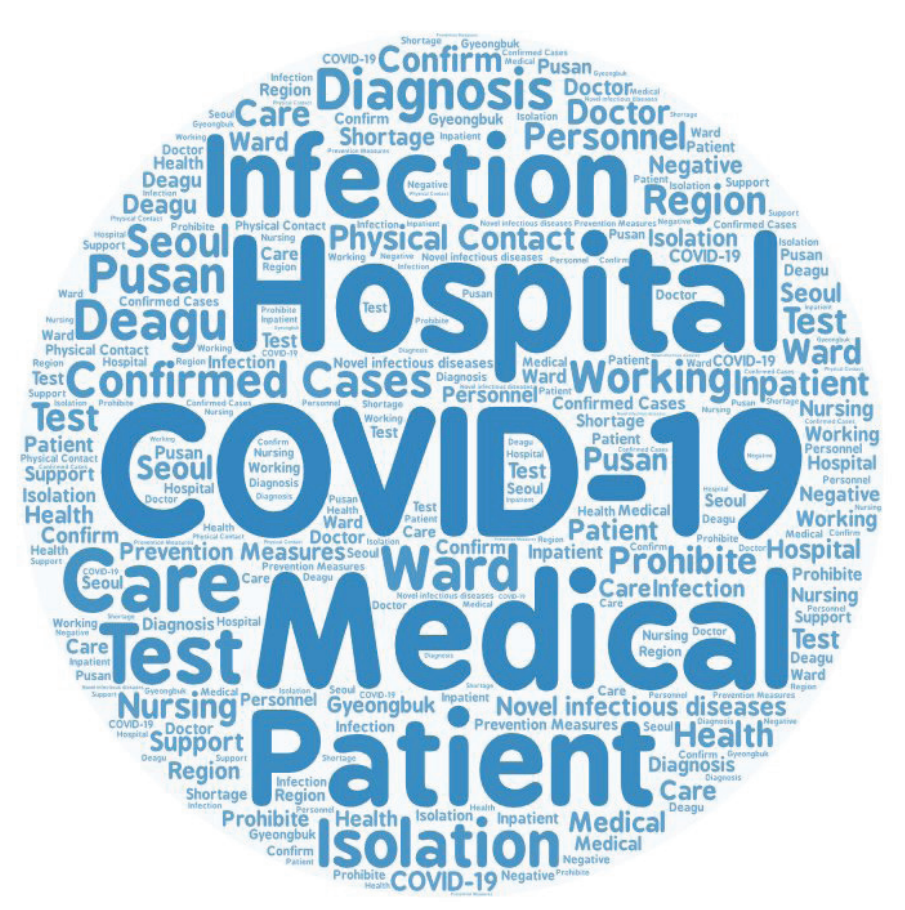

(b)

Figure 1. Word cloud of nurse-related keywords : before and after COVID-19: (a) Before COVID-19; (b) After COVID-19 


\section{Analysis of nurse-related keywords}

Among the nurse-related keywords identified in online newspaper articles before and after COVID-19, relevant keywords were derived and listed according to frequency (Table 2). Before COVID-19, the most frequently mentioned keywords were hospital $(12,525$ mentions), medical (5,953 mentions), patient $(4,680$ mentions), nursing (4,287 mentions), working (3,110 mentions), prohibit (2,737 mentions) workplace bullying
Medico-legal Update, October-December 2021, Vol.21, No. $4 \mathbf{2 2 3}$ (2,618 mentions), doctor (2,249 mentions), infant (2,075 mentions), and personnel (2,039 mentions). After COVID-19, the most frequently mentioned keyword were COVID-19 (7,278 mentions), hospital (5,955 mentions), medical (4,750 mentions), patient (3,930 mentions), infection (3,570 mentions), confirmed cases (2,698 mentions), diagnosis (2,517 mentions), isolation (2,292 mentions), care (2,039 mentions), and working (1,974 mentions).

Table 2. Results of nurse-related keywords by online news articles

\begin{tabular}{|c|c|c|c|c|c|c|}
\hline \multirow[b]{2}{*}{ Rank } & \multicolumn{3}{|c|}{ Before COVID-19 } & \multicolumn{3}{|c|}{ After COVID-19 } \\
\hline & Keyword & $n$ & $\%$ & Keyword & $n$ & $\%$ \\
\hline 1 & Hospital & 12,525 & 17.6 & COVID-19 & 7,278 & 12.4 \\
\hline 2 & Medical & 5,953 & 8.3 & Hospital & 5,955 & 10.2 \\
\hline 3 & Patient & 4,680 & 6.6 & Medical & 4,750 & 8.1 \\
\hline 4 & Nursing & 4,287 & 6 & Patient & 3,930 & 6.7 \\
\hline 5 & Working & 3,110 & 4.4 & Infection & 3,570 & 6.1 \\
\hline 6 & Prohibit & 2,737 & 3.8 & Confirmed cases & 2,698 & 4.6 \\
\hline 7 & Workplace bullying & 2,618 & 3.7 & Diagnosis & 2,517 & 4.3 \\
\hline 8 & Doctor & 2,249 & 3.2 & Isolation & 2,292 & 3.9 \\
\hline 9 & Infant & 2,075 & 2.9 & Care & 2,039 & 3.5 \\
\hline 10 & Personnel & 2,039 & 2.9 & Working & 1,974 & 3.4 \\
\hline
\end{tabular}

\section{Analysis of nurse-related keywords}

The nurse-related extraction results were classified into the five higher-order categories of place, character, specialty, relation, and work based on the characteristics of the keywords. Table 3 shows the frequencies by category and keyword before and after COVID-19.
This analysis reveals several keywords that began to appear only after COVID-19. For words related to place, "hospital" and "workplace" appeared most frequently before COVID-19. "Daegu," which had not appeared before COVID-19, appeared after COVID-19. For words related to character, the most frequently appearing words before COVID-19 were "patient" and "doctor," respectively. After COVID-19, they were "patient" 
and "personnel," respectively. For words related to specialty, the most frequently appearing words before COVID-19 were "medical" and "nursing," respectively. The word "COVID-19" emerged after the occurrence of COVID-19. For words related to relation, there was a significant difference between the most frequently appearing words before and after COVID-19. Before
COVID-19, "workforce bullying" and "death" were the most frequently used words, and the words "care" and "support" emerged after COVID-19. For words related to work, the word "workload" appeared before COVID-19, and the word "physical contact" appeared after COVID-19.

Table 3. Linking words by category

\begin{tabular}{|c|c|c|c|c|c|}
\hline \multirow{2}{*}{ Category } & \multirow{2}{*}{ Rank } & Linking word & n & Linking word & After COVID-19 \\
\hline Place & 1 & Hospital & 12,525 & Hospital & 5,955 \\
\hline \multirow{2}{*}{ Character } & 1 & Workplace & 1,339 & Deagu & 1,630 \\
\hline \multirow{2}{*}{ Specialty } & 2 & Patient & 4,680 & Patient & 3,930 \\
\hline & 1 & Doctor & 2,249 & Personnel & 1,364 \\
\hline Relation & 1 & Medical & 5,953 & COVID-19 & 7,278 \\
\hline & 2 & Nursing & 4,287 & Medical & 4,750 \\
\hline Work & 2 & Workplace bullying & 2,618 & Care & 2,039 \\
\hline & 2 & Dorking & 3,110 & Working & 1,974 \\
\hline
\end{tabular}

A word cloud was used to visualize the highly relevant keywords from the main nurse-related keywords used in online newspapers before

\section{Discussion}

In this study, the words simultaneously appearing with the word "nurse" were extracted from newspaper articles appearing on Naver, which is the most popular internet portal in Korea. The most frequent words related to place were "hospital," "workplace," and "Daegu." The newly emerged keyword "Daegu" is the area where the first COVID-19 case was diagnosed in Korea and is significant as a place where many nurses from all over the country volunteer to work as medical personnel. Among the places most frequently associated with nurses, the keyword "hospital" was ranked in the top 1-2 words both before and after COVID-19 indicating that the word "nurse" is still associated with hospitals. In a study by Kim \& Kim (2001), direct contact with nurses was found to affect the image of nurses held by $46.1 \%$ 
of the sample, while mass media affected the image of nurses held by $16.3 \%$ of participants ${ }^{[25]}$. Fortunately, a previous study found that experience in hospitals affected the image of nurses held by the majority of people, and nurses were viewed highly favorably by the patients or caregivers whom they had cared for directly ${ }^{[23]}$.

In the case of the most frequent words related to character, "patient" and "doctor" were ranked first and second, respectively, before COVID-19, and "patient" and "personnel" were ranked first and second, respectively, after COVID-19. Before COVID-19, "nurse" and "doctor" appeared with a high association on social networking websites such as Facebook and Twitter [19]. Conversely, after COVID-19, the words "patient" and "personnel" showed a high association with the word "nurse." This finding appears to reflect the situation in Korea after mid-February when the lack of nursing personnel due to the spike in the number of patients with COVID-19 was revealed. Sufficient human resources are a significant component of an effective working environment ${ }^{[26]}$. Nevertheless, there has not been significant improvement in the level of staffing for nurses despite the nursing community's insistence that adequate nursing personnel is crucial for patient outcomes ${ }^{[27,28]}$. The results of this study suggest the public may be beginning to show interest in the problem of the personnel shortage in nursing, which has so far only been noticed by the nursing industry, and this may be an ideal time to seek an increase in nursing personnel.

In the case of the most frequent words related to specialty, the word "COVID-19" emerged after COVID-19 in comparison to "medical" and "nursing" before COVID-19. This finding may reflect the current situation, in which nurses are actively serving as experts at the center of the COVID-19 response.

For the most frequent words related to place, character, and specialty, the image of nurses in internet newspaper articles before COVID-19 could be depicted as "with medical professionals, nursing patients in hospitals." Conversely, the image of nurses in internet newspaper articles as "personnel nursing COVID-19 patients in local hospitals in Daegu" has emerged after COVID-19.

For the most frequent words related to relation, there is a clear difference in the words used before and after COVID-19. "Workplace bullying" and "death" were the most frequently used words before COVID-19, and words such as "care" and "support" emerged after COVID-19. After COVID-19, positive words were predominant, whereas before COVID-19, negative words were the most frequently used. This finding may be because after COVID-19, most news reports were about the actual work of nurses whereas before COVID-19, a great deal of public attention was paid to several provocative incidents involving nurses. For instance, the death of a nurse from burns and the sexual harassment of nurses in the workplace are among the several incidents that had drawn public attention to nurses ${ }^{[29]}$. News reports of these incidents were not intended to reflect the everyday reality of nurses and nursing work, but rather to select and interpret the reality from a particular perspective, which explains why "workplace bullying" and "death" were highlighted as words related to nurses. As a result of such news reports, public opinion in Korea supports resolving the problem of workplace bullying at the government level.

In countries such as Sweden, Britain, Japan, Canada, and France, workplace harassment laws have been enacted and enforced, which is considered an effective approach to the issue ${ }^{[30]}$. Thus, a revision to the Labor Standards Act, including a ban on workplace harassment, was implemented in Korea beginning on July 16, $2019^{[31]}$. Although this law is not only for nurses, it is nevertheless a positive sign that a new law on workplace harassment has been introduced. However, to sustain the current positive image of nurses, the Korean nursing community needs to ensure that the recently implemented law results in specific policies that include site-oriented guidelines and standards.

In the case of the most frequent work-related words, the main finding was the appearance of the word "workload" before COVID-19 and the word "physical 
contact" after COVID-19. Keywords before COVID-19 were indicative of excessive nurse workload. According to the Health and Medical Workers" Union survey [32] conducted in 2016, the average daily break and mealtime for nurses was 29.7 minutes, which was 22 minutes shorter than for other healthcare professions, and the average monthly number of meals nurses skipped was 5.9, which is about three times as many as that for other healthcare professionals. Nurses were also working 19.5 minutes more in overtime than other healthcare professionals. Poor working conditions and high work intensity are considered to be the leading causes of harassment in the workplace and nurse turnover ${ }^{[33-35]}$. In fact, the number of graduates of nursing schools in Korea is 97.3 per 100,000 people, the highest among the OECD countries, but the percentage of graduates who are active nurses is $46 \%$, which is only half of the OECD average ${ }^{[36]}$. The government has tried to solve the shortage of nurses by increasing the number of nursing colleges to produce more nursing graduates ${ }^{[37]}$. However, unless the poor working conditions for nurses are improved, it will not be possible to solve the shortage of personnel caused by high turnover.

After the COVID-19 outbreak, the frequency of the keywords "care," "support," and "physical contact" resulted in a positive image of nurses. This finding is consistent with the purpose of nursing, the study of caring, and a positive image of nurses. In Yom's [23] study, the caring images of nurses were the most prevalent, and subjects who had been cared for by nurses had formed a good image of nurses. Also, Kalisch [38] reported that among the images of nurses on the internet, most were viewed as respectable, responsible, confident, and dedicated professionals.

The analysis of the most frequent words related to emotions and work showed that in general, the internet newspaper articles before COVID-19 gave an image of nurses as "receiving poor treatment for their work." However, in internet newspaper articles after COVID-19, the image of nurses as "positive professionals caring for and supporting the patients by their side in the medical field" was highlighted.
After the COVID-19 outbreak, the image of nurses in the field showed their expertise and ability to care for patients with autonomy. Therefore, the public's perception was likely more positive than the nurses themselves recognized, and their profession and expertise were acknowledged ${ }^{[39]}$. This change in perception has been subtle, but it is believed that the images of nurses working in the field have begun to be transmitted through mass media. However, it requires considerable time and effort to change a fixed image, but the speed at which information is shared on the internet may accelerate the change ${ }^{[40]}$. More importantly, it is necessary to examine the trends in nurse-related words in the future ${ }^{[23]}$ and focus on how they can be improved. The authors should discuss the results and how they can be interpreted from the perspective of previous studies and the working hypotheses. The findings and their implications should be discussed in the broadest context possible.

\section{Conclusion}

This study analyzed the image of nurses from nurserelated articles in Korean online newspapers. How the newspaper article interprets the role of nurses and delivers it to the public has a significant impact on the public's image of nurses. Therefore, it is significant that the analysis used Korean online newspaper articles about nurses. In terms of nursing research, this study is meaningful because it provides insights into changes in public awareness of nurses before and after COVID-19. Furthermore, as a country that has been responding to COVID-19 for a longer period than many other countries, Korea will be able to provide a reference for the image reconsideration of nurses struggling around the world through this analysis.

However, this study has many limitations due to data bias and restrictions in analytic methods. First, there was a data imbalance in the period before and after the COVID-19 outbreak and between each newspaper. In order to overcome this limitation, it is suggested that in future research, data is analyzed by the form of media and source of data in order to fully comprehend its meaning. Second, the subjective judgment of the researchers was 
involved in eliminating meaningless words or stop words while extracting nurse-related words from the data. In this study, the rule that the consent of two or more researchers is required to remove a word was applied. Nevertheless, it is suggested that objective criteria are employed regarding the treatment of meaningless words or stop words in the analysis of the data to minimize the effect of subjectivity on the results.

Further research is also needed to determine how the content of online newspaper articles actually affects the images of nurses. For example, comments posted on the internet may indicate how much the general public trusts and accepts the content of an article. In addition, research on other forms of media, not only in newspapers, should be actively conducted. It is also necessary to constantly monitor nurses described in mass media such as newspapers and seek ways to encourage positive news reports in newspapers, so the public does not form a negative or inaccurate image of nurses. We look forward to continuing the study the image of nurses and to becoming nurses who can respond quickly to the changes.

Ethical Clearance: For ethical consideration of the study subjects, Nothing specific-No IRB needed.

Source of Funding: This research received no external funding

Conflict of Interest: The authors declare no conflict of interest.

\section{References}

1. WHO Director-General's opening remarks at the media briefing on COVID-19. Available online: https://covid19.who.int/. (accessed on 24 May 2020).

2. Central Disaster and Safety Countermeasure Headquarters. Current Status of Response to COVID-19 and Future Plans. Available online: https://www.mohw.go.kr/eng/nw/nw0101vw. j s p ? PAR_MENU_ID $=1007 \& \mathrm{MENU}_{-}$ $\mathrm{ID}=100701 \&$ page $=1 \&$ CONT_SEQ $=354642$. (accessed on 24 May 2020).

3. Central Disaster and Safety Control Headquarters.
Coronavirus Disease-19. Available online: http:// ncov.mohw.go.kr/. (accessed on 24 May 2020).

4. Jackson D, Bradbury-Jones C, Baptiste D, Gelling L, Morin K, Neville S, Smith GD. Life in the pandemic: some reflections on nursing in the context of COVID-19. Journal of Clinical Nursing 2020; 29: 2041-2043.

5. Peplau HE. Interpersonal relations in nursing: A conceptual frame of reference for psychodynamic nursing. Springer Publishing Company: New York, USA, 1991.

6. Takase M, Kershaw E, Burt L. Does public image of nurses matter? Journal of Professional Nursing 2002; 18: 196-205.

7. Öhlen J, Segesten K. The professional identity of the nurse: Concept analysis and development. Journal of Advanced Nursing 1998; 28: 720-727.

8. Gregg MF, Magilvy JK. Professional identity of Japanese nurses: Bonding into nursing. Nursing and Health Science 2001; 3: 47-55.

9. Roviralta-Vilella M, Moreno-Poyato AR, Rodríguez-Nogueira Ó, Duran-Jordà X, RoldánMerino JF, MiRTCIME, CAT Working Group. Relationship between the nursing practice environment and the therapeutic relationship in acute mental health units: A cross-sectional study. International journal of mental health nursing 2019; 28: 1338-1346.

10. Na MS. Framing an issue of building a nuclear waste site on television news. Korean Journal of Communication \& Information 2004; 8: 157$208 . \quad \mathrm{https} / / / \mathrm{www} \cdot$ koreascience.or.kr/article/ JAKO200434335838997.page

11. Black BP. Professional nursing: Concepts and challenges. Saunders : Philadelphia, PA, USA, 2013.

12. Jeon, H.J. An Analysis of Risk Communication-A Case Study of MERS - CoV in Korea. Crisisonomy 2016; 12: 143-155. https://www.earticle.net/ Article/A276315

13. Donelan K, Buerhaus P, DesRoches C, Dittus R, Dutwin D. Public perceptions of nursing careers: The influence of the media and nursing shortages. Nursing Economics 2008; 26: 143-150. https:// www.researchgate.net/publication/5236756

14. Organisation for Economic Co-operation and Development. Available online: http://data.oecd. org/ict/internet-access.htm (accessed on 4 April 
2020).

15. Kim SH, Kim WG. Digital news report 2017 Korea [Internet]. Korea Press Foundation: Seoul, Korea, 2017. Available online: http://www.kpf.or.kr/site/ $\mathrm{kpf} / \mathrm{research} / \mathrm{selectMediaPdsView}$. do?seq $=574323$ (accessed on 2 March 2020).

16. Park SA, Park SJ, Lee CM, Yun MR, Hwang KY. Image of nurses portrayed in internet newspapers. Culture and Convergence 2017; 39: 677-700.

17. Seo, H.H. Analysis of nurses' image as portrayed in Korean online newspapers in association with the MERS outbreak. Master's thesis. Chung-Ang University, Seoul, 2017.

18. Park, SA, Kwon HJ, Kim HJ. The portrayal of nurses and physicians in hospital administration journals. Journal of Korean Clinical Nursing Research 2010; 16: 33-42.

19. Lee HS, Lee HS, Yom YH, Lee JM, Jung WS, Park HJ. A study of the image of nurse through analysing linking words of nurse in the internet and social media. Journal of Korean Clinical Nursing Research 2016; 22: 173-182.

20. Im ML. Research on contents analysis on image of nursing on television drama. Health \& Nursing 1995; 7: 64-83.

21. Kim JE, Jung HJ, Kim HN, Son SY, An SK, Kim SB, Son JE, Lee EJ, LEE HW, Jung MK, Jeon $\mathrm{KH}$. The image of nurses and their clinical role portrayed in Korean medical TV dramas in recent 5 years. Perspectives in Nursing Science 2013; 10: 120-132. http://hdl.handle.net/10371/86569

22. Kwon YA, Gil MJ, Kim JH, Chun KY, Yoo HJ, Jung JH. The image and activity of nurses on US medical dramas. Journal of Ehwa Nursing Academics 2009; 43: 1-16.

23. Yom YH, Kim KH, Son HS, Lee JM, Jeon JH, Kim MA. An analysis of the image of nurses portrayed on Korean TV dramas. Journal of Korean Clinical Nursing Research 2015; 21: 412-423.

24. Yoon S. Techno Populism and Algorithmic Manipulation of News in South Korea. Journal of Contemporary Eastern Asia 2019; 18: 33-48.

25. Kim HJ, Kim HO. A study on image of the nurse. Journal of Korean Academy of Nursing Administration 2001; 7: 97-109.

26. Lake ET. Development of the practice environment scale of the Nursing Work Index. Research in
Nursing \& Health 2002; 25: 176-188.

27. Cho E, Sloane DM, Kim EY, Kim S, Choi M, Yoo IY, Lee HS, Aiken LH. Effects of nurse staffing, work environments, and education on patient mortality: An observational study. International Journal of Nursing Studies 2015; 52: 535-542.

28. Aiken LH, Cimiotti JP, Sloane DM, Smith HL, Flynn L, Neff DF. The effects of nurse staffing and nurse education on patient deaths in hospitals with different nurse work environments. Medical Care 2011; 49: 1047-1053.

29. Medical Today. $70.6 \%$ of nurses without overtime payment ... free laber 'prevailing'. Available online: http://www.mdtoday.co.kr/mdtoday/index. html?no=315576 (accessed on 20 May 2020).

30. Gu MY, Cheon JY, Seo YJ, Jung, SG. Prevention of workplace bullying among women workers: Survey analysis and policy suggestions. Korean Women's Development Institute: Seoul, Korea, 2015 Oct. Report No.: TRKO201600001097.

31. Ministry of Employment and Labor. Labor standards law [Internet]. Ministry of Employment and Labor: Sejong, Korea, 2019. Available online: http://www. law.go.kr/1sSc.do?tabMenuId=tab18\#undefined (accessed on 16 May 2020).

32. Lee JS, Jung HJ, Ko HM, Kim HJ. Survey of health workers in 2016 -wage, working condition, working environment- [Internet]. Korea University Institute for Research on Labor and Employment: Seoul, Korea, 2016. Available online: http:// webcache.googleusercontent.com/search? $q=-$ cache:agF2gJrn7eYJ:www.kefplaza.com/labor/ down.jsp\%-3Fidx\%3D14384\%26fileId\%3D14012 $+\& \mathrm{~cd}=1 \& \mathrm{hl}=\mathrm{ko} \& \mathrm{ct}=-\mathrm{clnk} \& \mathrm{gl}=\mathrm{kr}$ (accessed on 20 May 2020).

33. Kang J, Lee M. The related factors to workplace bullying in nursing: A systematic review and metaanalysis. Korean Journal of Adult Nursing 2016; 28: 399-414.

34. Lee Y, Kang J. Related factors of turnover intention among Korean hospital nurses: A systematic review and meta-analysis. Korean Journal of Adult Nursing 2018; 30: 1-17.

35. Yun S, Kang J. Influencing factors and consequences of workplace bullying among nurses: A structural equation modeling. Asian Nursing Research 2018; 12: $26-33$.

36. Ministry of Health and Welfare. Ministry of 
Health and Welfare announced $\ulcorner$ An ambitious plan to improve nurses' working conditions $\lrcorner$ [Internet]. Ministry of Health and Welfare: Sejong, Korea, 2018. Available online: http://www.mohw. go.kr/react/al/sal0301vw.jsp?PAR_MENU $\mathrm{ID}=04 \& \mathrm{MENU}$ ID $=0403 \&$ page $=28 \& \mathrm{CONT}_{-}$ SEQ=344262 (accessed on 20 May 2020).

37. Park SJ. Nurse manpower shortage, why can't solve? [Internet]. Medical Observer: Seoul, Korea, 2016. Available online: http://www.monews.co.kr/ news/articleView.html?idxno=94693 (accessed on 20 May 2020)
38. Kalisch BJ, Begeny S, Neumann S. The image of the nurse on the internet. Nursing Outlook 2007; 55: 182-188.

39. Korean Gallop, Korean Nurses Association. Focus 02: Public opinion poll of nurse image. The Korean Nurse. 2006, 45, 6-7.

40. Song TM. Development of suicide search prediction model through analysis of social big data. Health and Welfare Policy Forum 2013; 8: 74-86. 